\title{
Characterisation of Staphylococcus intermedius isolates from canine pyoderma and from healthy carriers by SDS- PAGE of exoproteins, immunoblotting and restriction endonuclease digest analysis
}

\author{
R. P. ALLAKER†, N. GARRETT, LOUISE KENT**, W. C. NOBLE* and D. H. LLOYD \\ Dermatology Unit, Royal Veterinary College, Hawkshead Lane, North Mimms, Hertfordshire AL9 7TA, * Department \\ of Microbial Diseases, St John's Institute of Dermatology, St Thomas's Hospital, London SE1 7EH and †Department \\ of Oral Microbiology, The London Hospital Medical College, Turner Street, London E1 2AD
}

\begin{abstract}
Summary. Ten Staphylococcus intermedius isolates from cases of canine pyoderma and 10 from healthy carriers were examined by SDS-PAGE of exoproteins, immunoblotting and restriction endonuclease digest analysis. Similarities between banding patterns of the isolates were calculated as Dice coefficients for all three methods. For SDS-PAGE and immunoblotting, no significant differentiation was found between the pyoderma and "healthy" groups. Analysis of DNA digested with BglII indicated that $S$. intermedius is genetically heterogeneous; Dice coefficients for the pyoderma group were distinct from those for the healthy group ( $<<0.001)$, and cluster analysis confirmed that the pyoderma isolates (9) formed a group separate from the majority ( 6 of 9 ) of the normal isolates.
\end{abstract}

\section{Introduction}

Many factors have been suggested as contributing to the pathogenesis of canine pyoderma, including bacterial infection, impaired immunity, endocrine abnormalities, seborrhoea and allergic conditions. ${ }^{1}$ Staphylococcus intermedius is the predominant coagulase-positive staphylococcus isolated from nor$\mathrm{mal}$ and infected canine skin. ${ }^{2}$ Production of potential virulence factors, including haemolysins, enterotoxins, epidermolytic toxins, proteases and protein A, have been compared in $S$. intermedius isolates from healthy dogs and dogs with pyoderma.$^{3-5}$ However, no clear differences in the toxin profiles between these groups of isolates have been demonstrated.

In this study, $S$. intermedius isolates from healthy dogs and from canine pyoderma were examined by three methods: SDS-PAGE analysis of concentrated extracellular proteins (CEP); immunoblotting of CEP with hyperimmune rabbit serum; and DNA restriction fragment length polymorphism (RFLP) analysis. The banding patterns produced allowed comparison of phenotypic (SDS-PAGE of CEP; immunoblot) and genotypic (RFLP) characteristics of the two groups of isolates.

\section{Materials and methods}

\section{Bacterial isolates}

Skin isolates of $S$. intermedius were obtained from 20 distinct sources $;^{3} 10$ from clinically normal dogs and 10 from dogs classified as cases of superficial pyoderma according to Muller et al. ${ }^{1}$ Identification to species level was by the methods of Hajek. ${ }^{6}$ Isolates were maintained on Protect beads ( $\mathrm{Lab} \mathrm{M}$ ) at $-20^{\circ} \mathrm{C}$ until required.

\section{Preparation of samples}

Two culture methods were used. Exoproteins for SDS-PAGE and immunoblotting were obtained by culturing $S$. intermedius on the exterior of dialysis bags (c. $12 \mathrm{~cm} \times 5 \mathrm{~cm}$ ) containing $150 \mathrm{ml}$ of broth enclosed in glass flasks as described by Ikigai. ${ }^{7}$ Broth culture medium contained Tryptone (Oxoid, L42) $1.7 \% \mathrm{w} / \mathrm{v}$, yeast extract (Oxoid, L21) $1 \% \mathrm{w} / \mathrm{v}, \mathrm{NaCl} 0.5 \% \mathrm{w} / \mathrm{v}$ and $\mathrm{K}_{2} \mathrm{HPO}_{4} 0.25 \% \mathrm{w} / \mathrm{v}$. Cultures were incubated at $37^{\circ} \mathrm{C}$ in air for $24 \mathrm{~h}$ on a shaking platform $(100 \mathrm{rpm})$, the broth was centrifuged and the supernate was membrane filtered (Millipore; $0.45 \mu \mathrm{m}$ ) to remove residual cells. Supernate protein concentrations were measured by the BioRad Protein Assay and the supernate was diluted to a standard protein concentration $(3.63 \mathrm{SE} \quad 0.39 \mathrm{mg} / \mathrm{ml})$ for subsequent analyses. For RFLP analysis, isolates were grown on Blood Agar Base (Oxoid, CM271), and colonies were 
Table. Similarity matrices for pyoderma (DP) and healthy (DN) isolates in (A) SDS-PAGE exoprotein, (B) immunoblot and (C) BglII RFLP analyses

\begin{tabular}{|c|c|c|c|c|c|c|c|c|c|c|c|c|c|c|c|c|c|c|c|c|}
\hline & \multirow{2}{*}{$\begin{array}{l}\text { Isolate } \\
\text { no. }\end{array}$} & \multicolumn{19}{|c|}{ Percentage similarity with isolate no. } \\
\hline & & DP1 & $\mathrm{DP} 2$ & DP3 & DP4 & DP5 & DP6 & DP7 & DP8 & DP9 & DP10 & $\mathrm{DN} 23$ & $\mathrm{DN} 25$ & DN26 & DN31 & DN41 & DN47 & DN49 & DN51 & DN52 \\
\hline \multirow[t]{19}{*}{ A } & DN53 & 78 & 66 & 71 & 91 & 86 & 89 & 84 & 92 & 68 & 62 & 67 & 69 & 58 & 83 & 79 & 84 & 94 & 99 & 94 \\
\hline & DN52 & 83 & 76 & 90 & 87 & 88 & 87 & 86 & 86 & 92 & 64 & 72 & 71 & 54 & 89 & 80 & 87 & 95 & 90 & \\
\hline & DN51 & 71 & 67 & 76 & 92 & 95 & 90 & 83 & 93 & 79 & 57 & 59 & 67 & 56 & 82 & 77 & 83 & 75 & & \\
\hline & DN49 & 91 & 89 & 79 & 75 & 78 & 77 & 74 & 80 & 85 & 81 & 78 & 76 & 72 & 92 & 88 & 78 & & & \\
\hline & DN47 & 94 & 78 & 80 & 76 & 78 & 78 & 72 & 76 & 85 & 79 & 79 & 77 & 73 & 96 & 64 & & & & \\
\hline & DN41 & 94 & 87 & 83 & 76 & 78 & 80 & 77 & 78 & 83 & 79 & 75 & 85 & 73 & 68 & & & & & \\
\hline & DN31 & 93 & 83 & 79 & 75 & 77 & 79 & 74 & 75 & 87 & 76 & 81 & 83 & 68 & & & & & & \\
\hline & DN26 & 68 & 69 & 59 & 53 & 55 & 55 & 52 & 58 & 62 & 91 & 86 & 79 & & & & & & & \\
\hline & DN25 & 79 & 77 & 70 & 63 & 66 & 65 & 62 & 66 & 73 & 86 & 77 & & & & & & & & \\
\hline & DN23 & 77 & 78 & 68 & 61 & 64 & 63 & 60 & 64 & 68 & 90 & & & & & & & & & \\
\hline & DP10 & 80 & 81 & 76 & 74 & 94 & 72 & 73 & 85 & 84 & & & & & & & & & & \\
\hline & DP9 & 84 & 72 & 74 & 86 & 82 & 90 & 85 & 79 & & & & & & & & & & & \\
\hline & DP8 & 87 & 78 & 82 & 74 & 67 & 82 & 79 & & & & & & & & & & & & \\
\hline & DP7 & 81 & 77 & 72 & 75 & 81 & 82 & & & & & & & & & & & & & \\
\hline & DP6 & 83 & 68 & 67 & 69 & 71 & & & & & & & & & & & & & & \\
\hline & DP5 & 87 & 85 & 86 & 82 & & & & & & & & & & & & & & & \\
\hline & DP4 & 84 & 80 & 83 & & & & & & & & & & & & & & & & \\
\hline & DP3 & 81 & 87 & & & & & & & & & & & & & & & & & \\
\hline & DP2 & 80 & & & & & & & & & & & & & & & & & & \\
\hline \multirow[t]{19}{*}{ B } & DN53 & 77 & 79 & 76 & 80 & 84 & 78 & 80 & 87 & 81 & 86 & 65 & 81 & 72 & 73 & 82 & 89 & 84 & 82 & 95 \\
\hline & DN52 & 86 & 95 & 82 & 85 & 89 & 84 & 78 & 82 & 86 & 87 & 71 & 87 & 78 & 95 & 83 & 81 & 93 & 94 & \\
\hline & DN51 & 69 & 75 & 68 & 76 & 73 & 70 & 72 & 89 & 73 & 91 & 65 & 74 & 68 & 83 & 93 & 61 & 87 & & \\
\hline & DN49 & 78 & 83 & 77 & 88 & 89 & 83 & 85 & 78 & 82 & 87 & 74 & 78 & 77 & 95 & 86 & 81 & & & \\
\hline & DN47 & 80 & 88 & 75 & 89 & 87 & 78 & 75 & 86 & 65 & 88 & 61 & 77 & 72 & 86 & 87 & & & & \\
\hline & DN41 & 76 & 77 & 68 & 79 & 76 & 70 & 71 & 82 & 62 & 96 & 61 & 77 & 68 & 85 & & & & & \\
\hline & DN31 & 85 & 86 & 80 & 90 & 88 & 82 & 80 & 84 & 81 & 86 & 70 & 85 & 76 & & & & & & \\
\hline & DN26 & 81 & 87 & 85 & 80 & 81 & 98 & 85 & 70 & 81 & 69 & 89 & 86 & & & & & & & \\
\hline & DN25 & 91 & 88 & 86 & 85 & 94 & 84 & 86 & 79 & 74 & 78 & 80 & & & & & & & & \\
\hline & DN23 & 84 & 76 & 89 & 70 & 74 & 87 & 83 & 60 & 74 & 63 & & & & & & & & & \\
\hline & DP10 & 77 & 85 & 73 & 92 & 77 & 68 & 73 & 97 & 74 & & & & & & & & & & \\
\hline & DP9 & 95 & 83 & 86 & 81 & 90 & 98 & 93 & 77 & & & & & & & & & & & \\
\hline & DP8 & 75 & 83 & 70 & 81 & 84 & 72 & 70 & & & & & & & & & & & & \\
\hline & DP7 & 95 & 87 & 85 & 80 & 85 & 98 & & & & & & & & & & & & & \\
\hline & DP6 & 88 & 85 & 78 & 74 & 79 & & & & & & & & & & & & & & \\
\hline & DP5 & 90 & 87 & 85 & 84 & & & & & & & & & & & & & & & \\
\hline & DP4 & 85 & 86 & 80 & & & & & & & & & & & & & & & & \\
\hline & DP3 & 86 & 87 & & & & & & & & & & & & & & & & & \\
\hline & DP2 & 88 & & & & & & & & & & & & & & & & & & \\
\hline \multirow[t]{17}{*}{$\mathrm{C}$} & DN53 & 37 & 64 & 56 & 57 & 62 & 38 & 35 & 45 & 61 & & 54 & 36 & 64 & 30 & 69 & 48 & 45 & & 38 \\
\hline & DN52 & 42 & 27 & 36 & 56 & 61 & 33 & 40 & 53 & 40 & & 43 & 42 & 53 & 24 & 43 & 33 & 53 & & \\
\hline & DN49 & 40 & 52 & 52 & 54 & 50 & 55 & 48 & 50 & 38 & & 33 & 30 & 70 & 56 & 50 & 53 & & & \\
\hline & DN47 & 50 & 36 & 55 & 56 & 61 & 25 & 40 & 53 & 40 & & 35 & 21 & 63 & 59 & 35 & & & & \\
\hline & DN41 & 48 & 67 & 52 & 67 & 79 & 48 & 32 & 42 & 32 & & 50 & 33 & 50 & 36 & & & & & \\
\hline & DN31 & 42 & 29 & 48 & 42 & 36 & 43 & 34 & 56 & 63 & & 36 & 33 & 56 & & & & & & \\
\hline & DN26 & 48 & 43 & 52 & 46 & 50 & 73 & 48 & 30 & 29 & & 42 & 40 & & & & & & & \\
\hline & DN25 & 48 & 35 & 52 & 31 & 58 & 56 & 48 & 30 & 48 & & 33 & & & & & & & & \\
\hline & $\mathrm{DN} 23$ & 62 & 52 & 67 & 60 & 71 & 76 & 56 & 58 & 72 & & & & & & & & & & \\
\hline & DP9 & 69 & 50 & 33 & 59 & 64 & 62 & 64 & 67 & & & & & & & & & & & \\
\hline & DP8 & 48 & 52 & 52 & 62 & 42 & 45 & 57 & & & & & & & & & & & & \\
\hline & DP7 & 62 & 25 & 58 & 44 & 64 & 62 & & & & & & & & & & & & & \\
\hline & DP6 & 53 & 50 & 64 & 65 & 55 & & & & & & & & & & & & & & \\
\hline & DP5 & 62 & 52 & 67 & 67 & & & & & & & & & & & & & & & \\
\hline & DP4 & 55 & 48 & 41 & & & & & & & & & & & & & & & & \\
\hline & DP3 & 57 & 54 & & & & & & & & & & & & & & & & & \\
\hline & DP2 & 36 & & & & & & & & & & & & & & & & & & \\
\hline
\end{tabular}

harvested to yield $c .0 .4 \mathrm{~g}$ wet weight/isolate for subsequent DNA extraction.

\section{$S D S-P A G E$}

CEPs were analysed by the SDS-PAGE technique of Laemmli. ${ }^{8}$ Broth supernate was mixed in equal proportions with $1 \mathrm{M}$ Tris- $\mathrm{HCl}$, pH 6.8, containing SDS 3\% w/v, glycerol $15 \% \mathrm{w} / \mathrm{v}, 2$-mercaptoethanol $7.5 \% \mathrm{w} / \mathrm{v}$ and bromophenol blue tracking dye $0.0005 \% \mathrm{w} / \mathrm{v}$, boiled for $5 \mathrm{~min}$ and centrifuged to remove insoluble debris. The treated sample was applied to a well in an acrylamide $3.9 \%$ stacking gel over an acrylamide $12.5 \%$ resolving gel. Electrophoresis was performed with a discontinuous buffer system at room temperature in a vertical electrophoresis tank (model Protean II; BioRad). Constant current was used until the leading edge of the dye reached the resolving gel $(30 \mathrm{~mA})$ and the end of the gel $(40 \mathrm{~mA})$. Gels were stained with silver stain (BioRad).

\section{Immunoblotting}

Preparation of antiserum. Dialysis culture broth supernate from isolate DP10 $(1 \mathrm{ml})$ was mixed with $1 \mathrm{ml}$ of Freund's incomplete adjuvant (Sigma). Dutch rabbits were inoculated twice, with a 14-day interval, and bled at 28 days.

$C E P S D S-P A G E$ was performed as above, but with an acrylamide $10 \%$ resolving gel. Proteins were transferred from acrylamide gels to nitrocellulose membranes (BioRad) by overnight electrophoresis at room temperature in $25 \mathrm{~mm}$ Tris $-190 \mathrm{~mm}$ glycine buffer, $\mathrm{pH} 8 \cdot 3$, containing methanol $20 \% \mathrm{v} / \mathrm{v} .{ }^{9}$ Free protein-binding sites on the nitrocellulose were saturated by incubation for $1 \mathrm{~h}$ in blocking-washing buffer 


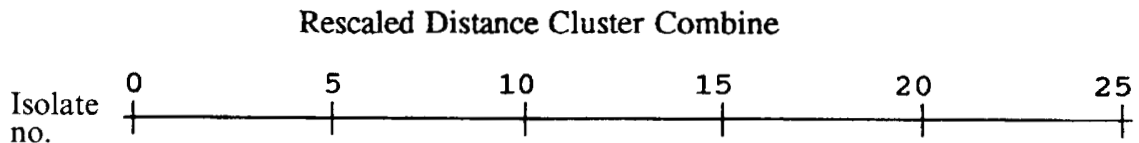

no.

DN51

DN53

DP8

DN49

DN52

DP4

DN31

DN47

DP6

DP9

DP7

DP5

DP10

DP1

DN41

DP2

DP3

DN23

DN26

DN25

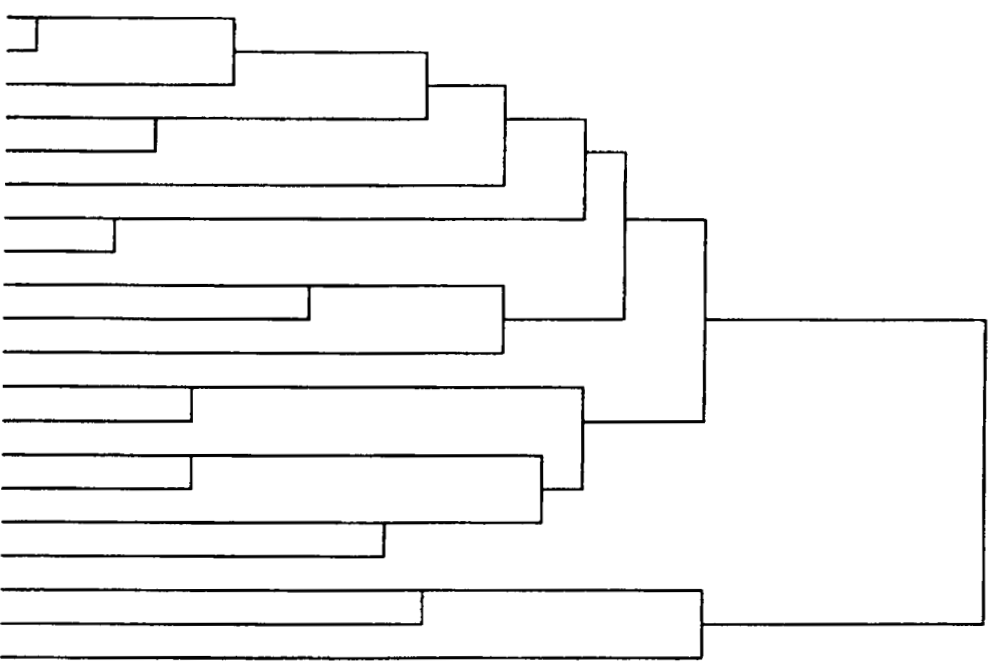

$\mathbf{A}$

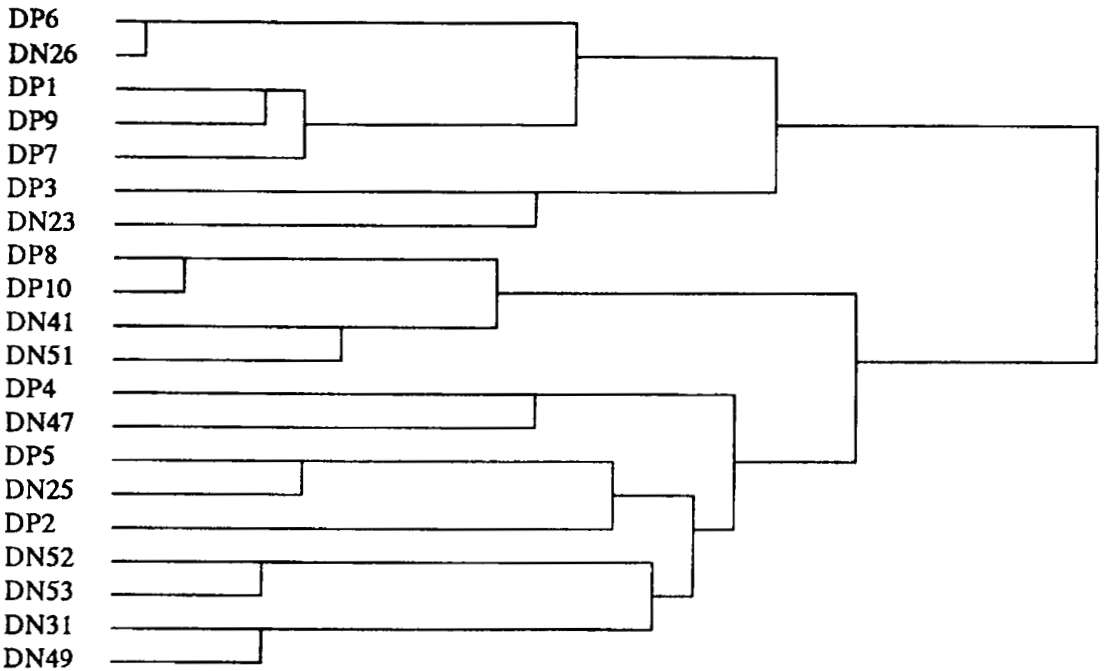

B

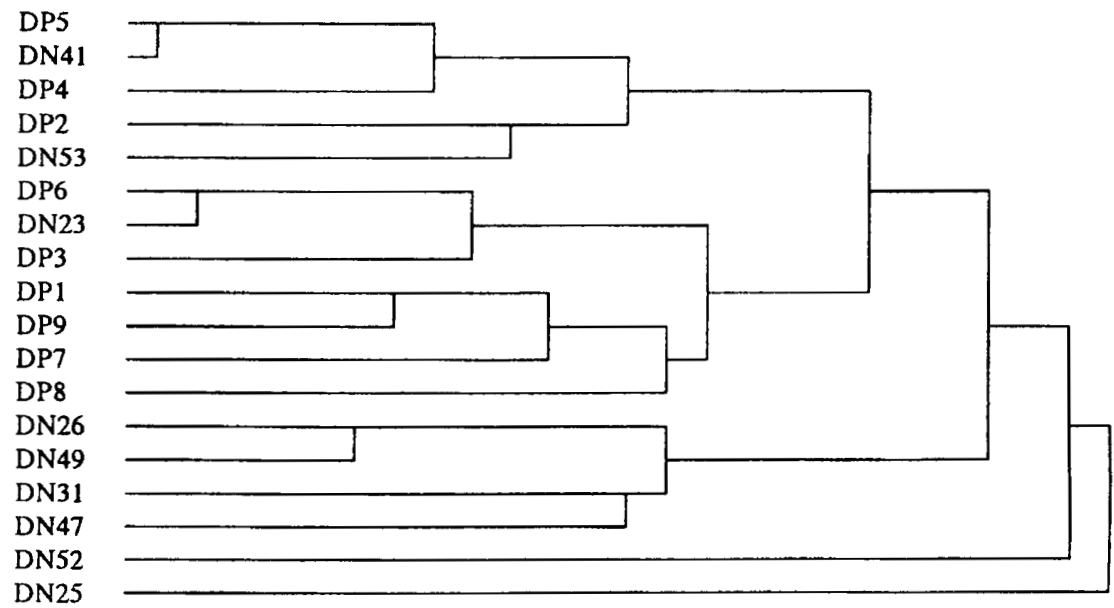

C

Figure. Dendograms obtained from cluster analysis of: (A) SDS-PAGE exoprotein; (B) immunoblot; and (C) $B g l$ II RFLP dice coefficient matrices for pyoderma (DP) and healthy (DN) isolates. Distances that clusters combine rescaled from (A) 69-99\%, (B) 77-98\% and (C) $40-79 \%$.

(phosphate-buffered saline, $\mathrm{pH} 7 \cdot 4$, plus Tween 20 $0.05 \% \mathrm{v} / \mathrm{v}$ ) with fetal calf serum (Gibco) $5 \% \mathrm{v} / \mathrm{v}$. The membrane was incubated for $1 \mathrm{~h}$ with rabbit antiserum (diluted 1 in 50), washed and incubated for $1 \mathrm{~h}$ with goat anti-rabbit IgG biotin conjugate (Sigma; diluted 1 in 250). Membranes were then washed and incubated 
with streptavidin-biotin-horseradish peroxidase complex for $30 \mathrm{~min}$. Staining was with diaminobenzidine tetrahydrochloride (Sigma).

\section{Restriction endonuclease analysis}

Chromosomal DNA was extracted by the guanidium thiocyanate method, ${ }^{10}$ modified to exclude plasmid DNA by the addition of Brij $581 \% \mathrm{w} / \mathrm{v}$, sodium deoxycholate $0.4 \% \mathrm{w} / \mathrm{v}$ and EDTA $2 \% \mathrm{w} / \mathrm{v} .{ }^{11}$ Extracted DNA was digested with the restriction enzymes HaeIII, BglII or EcoRI, according to the manufacturer's instructions (Pharmacia and Gibco BRL). Digest fragments were separated by horizontal electrophoresis in agarose $(1 \% \mathrm{w} / \mathrm{v})$ gel at a constant $40 \mathrm{~V}$ for $20 \mathrm{~h}$. A 1-kb DNA ladder (Gibco BRL) was used as a marker, with bromophenol blue as the tracking dye. Gels were stained with ethidium bromide and photographed under UV light.

\section{Numerical analysis of banding patterns}

The similarity between the banding patterns was calculated as a Dice coefficient, ${ }^{12}$ relating the number of common bands to the total number of bands present. Banding patterns were compared within gels for the two isolate groups run on successive occasions under strictly standardised conditions. Dice coefficients were compared in the Mann-Whitney test, and cluster analysis performed (average linkage between groups) in the Statistical Package for Social Sciences (PC version).

\section{Results}

CEP-SDS-PAGE patterns for all 20 isolates showed similarities $>50 \%$ (mean $78 \%$; table, $A$ ), and immunoblot patterns showed similarities $>60 \%$ (mean $81 \%$; table, B). However, there were no consistent, significant pattern differences between the pyoderma and healthy groups in either method (figure $A$ and $B$ ).

Of the endonuclease enzymes, EcoRI digestion gave well resolved bands for all isolates, but nondiscriminatory band patterns, and HaeIII gave too many bands for clear interpretation. $B g l$ II gave interpretable band patterns between $3 \cdot 1$ and $7 \cdot 1 \mathrm{~kb}$, with good interstrain discrimination. However, two strains (DP10 and DN51) did not give restriction patterns.

Similarities calculated from the $B g l I I$ digest patterns varied between 20 and $80 \%$ (table, C). Strains of the pyoderma group (mean $55 \%$ ) were significantly ( $p<$
0.001) more similar to one another than strains of the healthy group (mean $44 \%$ ). Indeed, the strains of the healthy group were clearly heterogeneous, so much so that mean similarities within this group were as low as the mean similarities between individual members of the healthy group and the pyoderma group. In cluster analysis, all the pyoderma isolates grouped together, along with three healthy isolates (figure, $\mathrm{C}$ ).

\section{Discussion}

The complexity of the exoprotein profiles made a detailed comparison of strains difficult. Although the immunoblot technique produced much simpler patterns, subdividing the isolates according to immunoblot or SDS-PAGE differences was difficult, as no constantly variable antigens or proteins could be identified. Certain band differences between isolates may be due to the limits of detection of the method, rather than the presence or total absence of the protein.

In endonuclease digest analysis, discrimination varied depending on the restriction enzyme used. DNA fingerprints from EcoRI digestion were identical, but $B g l$ II gave strain-specific digestion patterns. However, not all isolates could be analysed with $B g l$ II. The chromosomal DNA from strains DP10 and DN51 remained intact after incubation with $B g l \mathrm{II}$, but were readily restricted with $E c o$ RI. Resistance to digestion with $B g l$ II has also been reported for the chromosomal DNA of phage Group II $S$. aureus strains. ${ }^{13}$ This resistance may be explained by a different methylating system employed by these strains, protecting the DNA from restriction at these sites. This concept has recently inspired the conversion of common restriction enzymes to "rare cutters" by methylating the majority of restriction sites previously available to them. ${ }^{14}$

It is possible that dogs carry more than one strain of $S$. intermedius ${ }^{15}$ and perhaps those isolates possessing the required virulence determinants may be able to initiate disease, or are selected for, under the correct environmental conditions. The isolates examined in this study have been assayed for the production of a range of potential virulence factors. ${ }^{3}$ However, there was no obvious correlation between production of these factors and either the cluster patterns presented here, plasmid carriage (unpublished observations) or the pathogenic origin of the strains. It would appear that recognised staphylococcal toxins are not important virulence markers in canine infections with $S$. intermedius. A novel toxin or other unrecognised factors may be involved.

These studies were supported by a grant from the Wellcome Trust no. 19683/1.5. The authors also gratefully acknowledge M.J. Cottee, University of Hertfordshire, for assistance with the statistical analysis. 


\section{References}

1. Muller GM, Kirk RW, Scott DW. Small animal dermatology, 4th edn. Philadelphia, Saunders. 1989.

2. Berg JN, Wendell DE, Vogelweid C, Fales WH. Identification of the major coagulase-positive Staphylococcus sp. of dogs as Staphylococcus intermedius. Am J Vet Res 1984; 45: 1307-1309.

3. Allaker RP, Lamport AI, Lloyd DH, Noble WC. Production of 'virulence factors' by Staphylococcus intermedius isolates from cases of canine pyoderma and healthy carriers. Microb Ecol Hlth Dis 1991; 4: 169-173.

4. Allaker RP, Grzywacz M, Lloyd DH. Proteolytic zymograms of Staphylococcus intermedius isolates from cases of canine pyoderma and healthy carriers. Microb Ecol Hlth Dis 1992; 5: $163-165$.

5. Fehrer SL, Boyle MD, Halliwell RE. Identification of protein A from Staphylococcus intermedius isolated from canine skin. Am J Vet Res 1988; 49: 697-701.

6. Hajek V. Staphylococcus intermedius, a new species isolated from animals. Int $J$ Syst Bacteriol 1976; 26: 401-408.

7. Ikigai H, Seki K, Nishihara S, Masuda S. Simplified method for preparation of concentrated exoproteins produced by Staphylococcus aureus grown on surface of cellophane bag containing liquid medium. Microbiol Immunol 1988; 32: 225-228.

8. Laemmli UK. Cleavage of structural proteins during the assembly of the head of bacteriophage T4. Nature 1970; 227: 680-685.

9. Burnette WN. "Western Blotting": electrophoretic transfer of proteins from sodium dodecyl sulphate-polyacrylamide gels to unmodified nitrocellulose and radiographic detection with antibody and radioiodinated protein A. Anal Biochem 1981; 112: 195-203.

10. Pitcher DG, Saunders NA, Owen RJ. Rapid extraction of bacterial genomic DNA with guanidium thiocyanate. Lett Appl Microbiol 1989; 8: 151-156.

11. Clowes RC. Molecular structure of bacterial plasmids. Bacteriol Rev 1972; 36: 361-405.

12. Dice LR. Measures of the amount of ecologic association between species. Ecology 1945; 26: 297-302.

13. Richardson JF, Noble WC, Marples RR. Species identification and epidemiological typing of the staphylococci. In: Board RG, Jones D, Skinner FA (eds) Identification methods in applied and environmental microbiology, Blackwell Scientific Publications for The Society for Applied Bacteriology. Oxford, Blackwell. 1992: 193-219.

14. Kur J, Koob M, Burkiewicz A, Szybalski W. A novel method for converting common restriction enzymes into rare cutters: integration host factor-mediated Achilles cleavage (IHF-AC). Gene 1992; 110: 1-7.

15. Wegener HC, Pedersen $K$. Variations in antibiograms and plasmid profiles among multiple isolates of Staphylococcus intermedius from pyoderma in dogs. Acta Vet Scand 1992; 33: 391-394. 